Социология

DOI: $10.17805 /$ trudy.2015.5.1

\title{
КОММУНИКАЦИОННОЕ ВЛИЯНИЕ НА СОВРЕМЕННЫЕ СОЦИАЛЬНЫЕ ИЗМЕНЕНИЯ
}

\author{
Э. Ф. Макаревич \\ (Московский гуманитарный университет)
}

Аннотация: В статье анализируется феномен коммуникационной культуры, которая стала движущей силой социальных изменений. Рассматриваются особенности современной информационной среды, механизм коммуникационного влияния.

Ключевые слова: коммуникационная культура; информационная среда; информацзионное общество; фактор социальных изменений; информация

\section{COMMUNICATIVE IMPACT ON CONTEMPORARY SOCIAL CHANGE}

\author{
E. F. Makarevich \\ (Moscow University for the Humanities)
}

\begin{abstract}
The article addresses the phenomenon of communicative culture which has become the driving force of social change. We examine the specific features of contemporary information environment, as well as the mechanism of communicative impact.

Keywords: communicative culture; information environment; information society; factor of social change; information
\end{abstract}

\section{Коммуникационная культура и социальные изменения}

В наши дни меняется сама движущая сила социальных изменений. Ею становятся информационная среда, несущая определенные образы посредством информационных технологий, позволяющих эффективно реагировать на вызовы цивилизации - высокотехнологичной и рыночной. Анализ изменения системы ценностей европейской цивилизации в информационную эпоху показывает, что движущая сила ее развития основательно смещается в сферу изменений сущностей, влияния на людей, в сферу «обработки людей людьми», которая становится тотальной. Эти вызовы информационной эпохи формируют новое поколение лиде- 
ров массовой коммуникации, а отсюда - новое качество власти. Власть все более опирается на культуру управления массами. Если в прошлые столетия во взаимоотношениях с обществом власть чаще рассчитывала на насилие, то ныне она находит опору в культуре влияния на массового человека, в развитии массовых коммуникаций. Среди различных видов культуры - материальной, общественно-политической, жизнеобеспечения - все более доминирует культура массовых коммуникаций - культура влияния на человека. И умение управлять этой культурой приобретает принципиальное значение (Карпухин, 2012).

Регулируемая циркуляция информации внутри общества, включенность в систему образования все больших слоев населения, интенсивное развитие СМИ, Интернета, рекламы, массовой культуры - все это становится непременными инструментами власти, без которых она не может выполнять свои функции. Причем, это касается любой власти - политической и экономической, центральной и региональной.

Все более мощь и сила власти оценивается не столько по мощи административного аппарата и наличию материальных ресурсов, состоянию производительных сил, сколько по широте использования технологий массовых коммуникаций, обладающих культурой влияния на человека. Все заметнее становится, что не примат промышленных технологий, объемов производства и организации труда, не энергоресурсы, не выверенная структура власти, не силовые структуры, а массовые коммуникации «держат» общество. Говоря словами Ю. Хабермаса, пришла пора не «полагаться на разум производительных сил, т. е. в конечном счете на разум естествознания и техники», а больше доверять «производительной силе коммуникации, которая наиболее отчетливо выражается в борьбе за социальное освобождение» (Хабермас, 1996: 83-84). Именно производительная сила коммуникаций в значительной степени определяет уровень свободы и демократии общества, его справедливость, его альтруизм, его обращенность к человеку.

Здесь во всей полноте встает вопрос о культуре массовых коммуникаций, в основе которой философия свободы, которая проявляется в отношении к человеку. Либо это стимулирование абсолютной свободы личности или системы, возведенной в принцип, либо стимулирование свободы развития личности в гармонии с системой.

Представим, что эта философия коммуникаций держится на концепции информационного обмена взаимодействующих систем и подсистем, о которой в свое время говорил Т. Парсонс (Парсонс, 2000; см. также: Громов и др., 1996). Ключевая идея концепции Парсонса заключается в том, что катализатором социальных процессов является информационный обмен взаимодействующих систем и подсистем. Отношения между системами и подсистемами общества и внутри них представляют собой 
обмен информацией - совокупностью символов, вызывающих структурные изменения в системах. Из этого следует, что любой организм, будь то человек, семья или страна, сможет жить, развиваться, если между его частями, системами и подсистемами есть сбалансированный информационный обмен. Стоит разрушить этот обмен, то есть добиться преобладающего движения информации в одну сторону, достичь абсолютной свободы ее - и организм скоро достигает состояния неуправляемого хаоса. Жизнь социальной системы зависима от той философии, которой придерживаются массовые коммуникации.

Трагическая судьба одной из самых больших мировых социальных систем - Советского Союза - была обусловлена угасанием культуры, интеллектуальной мощи его массовых коммуникаций, угасанием критического знания, оказавшихся неспособными обеспечить полноценный информационный обмен между властью и обществом. Причем обеспечить на метаязыке, т. е. на языке, объединяющем все возрасты и социальные группы. Власть и общество не понимали, не слышали друг друга. Система коммуникаций стремилась к абсолютной свободе и стала «системой» хаоса. Она в конце концов пала, а за ней и страна. Новую информационную систему (и новую страну) создавали более удачливые лидеры, которые восстановили баланс информационной свободы, язык которых («права человека», «частная собственность», «рынок, который отрегулирует производство и накормит всех» и т. п.) был принят публикой. Трагедия была в том, что «новые» массовые коммуникации придерживались того же принципа абсолютной свободы. И это создало кризис в новой России, который пришлось преодолевать новой власти.

Т. Парсонс выдвинул крайне важный тезис: любая система контролируется такой подсистемой, которая обладает большим информационным потенциалом и потребляет наименьшее количество энергии. Это утверждение имеет прямое отношение к структурам, контролирующим массовые коммуникации, где на первых ролях находятся управленческие структуры «паблик рилейшнз» (PR). Если некая подсистема контролирует массовые коммуникации, но не с позиции цензуры, а посредством постоянного предложения на понятном всем языке конкурентоспособных идей и смыслов, искусно инициированных конкурентоспособными коммуникативными лидерами для решения острейших проблем, обсуждаемых обществом, то такая система не дряхлеет, а, напротив, усиливает свой информационный потенциал, способствует развитию культуры коммуникативной демократии.

Коммуникационная культура как философия коммуникаций предполагает определенные ценности, которым она следует, ориентируясь на принцип свободы (Макаревич, Карпухин, 2008аb). Но массовые коммуникации отнюдь не являются крепостью этих ценностей, которые изменя- 
ются в своей сути во времена постмодерна. Речь идет об общечеловеческих, нравственных ценностях. Растворение добра во зле, справедливости в несправедливости, общественного в собственническом индивидуализме, переходящим в агрессивный эгоизм. В рыночной сфере - это крепнущая тенденция, идущая от производства простого и сложного продукта к производству денег, это аморальность рынка, на котором игроки в погоне за максимальной прибылью готовы к забвению морали, и это согласуется с неолиберальным мышлением. В постигшем мир финансовом кризисе 2008-го и последующих годов значительная роль принадлежит безответственному поведению банков, «которое следует считать безответственным, поскольку оно предполагало отказ от важных практик проверки и учета; однако миллионы людей получали выгоду, покупая реальные товары и услуги за нереальные деньги, «произведенные» банками» (Крауч, 2012: 178). Такой вывод делает профессор экономической социологии Уорикского университета Колин Крауч в своей книге «Странная не-смерть неолиберализма». Он подчеркивает, «что практически все общества сначала стали соучастниками этих безответственных практик» (там же: 179). Следуя его логике, можно сказать, что неолиберализм завел нас в ценностную ловушку. Сущность этой ловушки можно понять, присмотревшись к нынешней ситуации с государством всеобщего благосостояния. Правительствам приходится значительно сокращать затраты на социальные услуги, на программы в области здравоохранения и образования, на пенсионное обеспечение и социальные выплаты неимущим и безработным. Правительства вынуждены идти на такие меры с целью успокоить финансовые рынки, встревоженные объемом государственного долга, хотя дельцы на этих рынках - это те самые люди, которые нажились на спасении банков и уже начали выплачивать самим себе огромные бонусы - «заработанные» благодаря тому, что их операции были застрахованы от риска государственными расходами, которые как раз и привели к государственному долгу» (там же: 179-180).

В России ценности постмодерна произросли в период реформ Б.Ельцина, послуживших появлению предпринимателей, одержимых безудержным, хищническим обогащением, лишенных сострадания, сопереживания с народом, солидарности с ним. «Дикий» российский капитализм, порожденный ими, вел себя в мировом финансовом кризисе также безответственно, как и «западный» капитализм, о котором пишет К. Крауч. Разве капитализм, лишенный морали, не способствует хаосу в умах, и в конечном счете, в обществе? Аморальный российский капитализм, как порождение постмодерна в России, постоянно напоминает о проблеме легитимности российского бизнеса, о легитимности бизнес-элиты, элиты политической, защищающейся громкими «моральными» заявлениями. Постмодерн, обрушивший мораль в обществе, обрушил и его единство, его 
солидарность, раздробив его на множество групп и группочек со своими ценностями, чаще всего индивидуального толка, находящимися в противостояниями друг с другом. И даже единственный объединяющий страну праздник - День Победы над германским фашизмом подвергся постмодернистской эрозии. Отношение к нему не отличается единством - одни отдают дань этой победе, другие думают, что немецкие нацисты дали бы русским людям богатую жизнь, третьи считают, что победа принадлежит США и Англии, а четвертые стремятся доказать, что и победы не было.

Современный капитализм подошел к такой стадии своего развития, когда он все меньше обращается к традиционным ценностям, потому что они не соотносятся со спекуляцией деньгами и акциями, с производством денег ради денег, с торговлей человеческими органами, с попытками клонирования людей. Появление капитализма и капиталистов, презирающих традиционные ценности, прогнозировали еще Маркс и Энгельс в своем манифесте коммунистической партии: «В ледяной воде эгоистического расчета потопила она [буржуазия. - Э. M.] священный трепет религиозного экстаза, рыцарского энтузиазма, мещанской сентиментальности. Она превратила личное достоинство человека в меновую стоимость и поставила на место бесчисленных пожалованных и благоприобретенных свобод одну бессовестную свободу торговли» (Маркс, Энгельс, 1961: 178).

Постмодерн как идеология и практика, нарушил баланс между ответственностью и безответственностью, а по сути, между мерами добра и зла, баланс между традиционной моралью и правом. И это нарушение ведет к хаосу в общественных и личных отношениях. Размывается культура чувств, которую художественно исследовали У. Шекспир, А. С. Пушкин, Л. Н. Толстой, А. П. Чехов, И. С. Бунин. Под флагом новых ценностей разрушается традиционная семья. В Европе крепнет тенденция легализации однополых браков с правом усыновления и удочерения. При этом в документах, регулирующих этот процесс, настойчиво подчеркивается, что необходимо избавиться от упоминания пола. Мужчины и женщины в интерпретации представленной в этих документах, становятся вымышленными бесполыми существами - родитель А, родитель Б. Легализация браков между представителями сексуальных меньшинств, как новая «семейная» ценность, стимулирует запреты на существующие гендерные стереотипы, согласно которым мать - это хранительница домашнего очага, отец - кормилец семьи. В некоторых европейских столицах системы образования и воспитания основаны на том, чтобы мальчики и девочки в возрасте до шести лет не ассоциировали себя с определенным полом. Детские сказки создают образы принцев, влюбляющихся в принцев; образы принцесс - любящих принцесс, образы королей, общающихся в нетрадиционной манере со своим окружением и детьми. Среди первых 
оппонентов подобной постмодернистской практики и законов, регламентирующих однополые браки, - почти все религиозные конфессии. Они первые борцы за традиционные ценности.

В своем крайнем выражении постмодерн делает зло абсолютным. Дьявол в людях побеждает, человек человеку все больше - волк, человек - природе тоже волк. И природа отвечает мщеньем, и человек в человеке видит врага. В свое время об опасности войны всех против всех писал английский философ Томас Гоббс. Постмодерн, зараженный бациллой войны всех против всех, формирует идеологию безысходности, идеологию античеловечности. При этом, идеологию, как совокупность взглядов, концептов, идей, в постмодерне выражают, а то и заменяют символы, словастимулы. Символы выражают смысл в абсолютном выражении. Если свобода - то «чистая», без ответственности; если демократия - то без границ. Управление символами, т. е. коммуникациями, есть «паблик рилейшнз». У.Липпман выразился вполне определенно: символы собирают эмоции, до этого отъединенные от своих идей, т.е. в какой-то период символы нужно отделить от смысла, от проблем их породивших, дающих им развитие.

Но когда управление символами находит свое проявление в беспрецедентном росте влияния массовых коммуникаций (что является особенностью постмодернистского этапа), символ превращается в код. На этом настаивал Ж. Бодрийяр. Если символ выражает объект, явление, событие, то код полностью замещает их. И теперь объект, явление или событие превращается в «гиперреальность», в модель, в образ (по Бодрийяру - в симулякры), в мифоимидж. Стирается грань между естественным и искусственным. Управляемый хаос сменяющихся образов «захватывает» личность, лишая ее опорных нравственных констант, будь то убеждения, традиции, память, не оставляя ничего святого ни в политике, ни в этических ценностях, ни в культуре, ни в искусстве.

Постмодернизм определяется принципом «движение - все, цель ничто» или «хаос - все, цель - ничто». При этом постмодерн как идеология и эстетика развития ориентируется все больше на рациональноинструментальное знание, а массовые коммуникации все чаще обращаются к бессознательному, к инстинктам, к эмоциям. В этом - новая культура коммуникаций: отречение от святынь, потеря ориентиров в калейдоскопе образов, чтобы манипулирование людьми достигло высших пределов, когда человек не замечает, как его поведение, жизнь меняются вопреки его воле, надеждам, интересам. И это - новый этап развития массового общества - глобальный, этап «виртуальной реальности», когда реальность тонет в виртуальных образах и в такой интерпретации становится частью жизненного уклада человека.

И когда Ф. Энгельс писал, что для «диалектической философии нет 
ничего раз и навсегда установленного, безусловного, святого» (там же: 276), он имел в виду то, что именно диалектика, как метод познания, позволяет подвергать анализу, исследованию все в этом мире, в том числе любые святыни. Но отречение от святынь, как свойство постмодерна, подразумевает совсем другое, а именно - изменение под влиянием виртуальных образов этических установок индивидов, определяющих их поведение. Изменение, связанное с отречением от традиционных ценностей, прежде всего нравственных.

Впрочем, человеку оставлено право на основе этих виртуальных образов объединяться с другими людьми, минуя государственные границы, на платформе новых ценностей. Индивидуальности, самобытности трудно противостоять постмодернистскому, глобальному потоку «виртуальной реальности».

\section{Механизм коммуникационного влияния в объяснении В. Бехтерева, Э. Ноэль-Нойман и А. Чехова}

Воздействие информации на внутренний мир личности - это есть процесс убеждения и внушения. Обратимся к авторитету выдающегося русского психиатра и психолога академика В. Бехтерева (если на Западе в изучении сферы сознательного и бессознательного главенствовали 3.Фрейд и К. Юнг, то в России в этой сфере научным лидером был В. Бехтерев). Исходя из взглядов Бехтерева (Бехтерев, 2001: 17-28), убеждение и внушение являются двумя основными формами влияния одного лица на другое. Такой подход применим и в массовых коммуникациях. Информация, попав в сферу личного сознания, воспринимается весьма активно, к ней вырабатывается определенное отношение. Все входящее в сферу личного сознания подвергается критике, переработке, что приводит к выработке убеждения. Это так называемый аффективный уровень восприятия информации. Убеждение действует на человека силой логики, фактов, аргументации, которые «перерабатываются» личным сознанием.

А вот в сфере общего сознания информация из внешнего мира воспринимается пассивно. Поэтому в процессе внушения (суггестивный уровень восприятия информации) влияние на психическую сферу человека осуществляется посредством восприятия психических состояний других людей, т. е. «чувствований и ощущений», и не требует участия личного сознания и логики. По Бехтереву, внушение сводится к непосредственному «прививанию» тех или иных психических состояний от одного лица другому, что происходит без участия воли воспринимающего лица и нередко даже без ясного с его стороны осознания происходящего (там же: 160-162). Главный элемент внушения - непосредственное воздействие. Будет ли внушение производиться посредством слова (пример - церков- 
ные проповеди) или посредством какого-либо явления либо действия, оно влияет на людей не логикой убеждения, а воздействием на психику.

Бехтерев особо подчеркивает, что и в убеждении, и во внушении велика роль примера. С одной стороны, пример действует на разум путем убеждения в полезности того, что человек видит и слышит. С другой стороны, пример может действовать и наподобие «психической заразы», иначе говоря - путем прямого внушения, как невольное и совершенно безотчетное подражание, заражение. Заражающие примеры может давать литература и искусство.

Но время меняет соотношение словесных и визуальных образов. Главный редактор «New Perspectives Quarterly» Н. Гардельс говорит, что Америка стала страной посттекстуальной культуры. Большинство людей получают информацию через образы (имеются в виду визуальные образы). Американцы воспринимают мир эмоционально и нерационально, с помощью того, что действует на них метафорично. Это прежде всего телевидение, кино, реклама. Поэтому процесс убеждения все чаще уступает место процессу внушения. В этом же направлении движется и Россия. На действенность убеждения или внушения оказывают влияние психофизиологические особенности человека, менталитет целевых групп с их ситуационными состояниями.

Но прежде чем личность, обрабатывая полученную информацию, придет к окончательному решению, подсказывающему ей, как поступить, она должна преодолеть еще один барьер - общественное мнение. То есть между ценностями, потребностями, интересами личности и ее действиями «вклиниваются» мнения других людей, влияющие на результат убеждения и внушения аудитории. Идеи, мысли, образы, «поставляемые» прессой, радио, телевидением или Интернетом, усваиваются большинством людей под влиянием находящихся рядом с ними, как правило, неформальных, но влиятельных «лидеров общественного мнения». Кто такие лидеры общественного мнения? Они из той же среды, из той же целевой аудитории, но отличаются активностью, высокой энергетикой в своих суждениях. Они заражают людей своим видением ситуации, своей позицией. По данным ФОМ (на конец 2012 г.), 58\% интернет-пользователей прислушиваются к онлайн-отзывам и рекомендациям других людей. По данным ВЦИОМ (на конец 2012 г.), порядка 62\% пользователей доверяют отзывам в социальных сетях, $47 \%$ верят советам на форумах и блогах, и 48\% ориентируются при выборе чего-либо на отзывы на сайтах (Социальные сети ..., 2013: Электр. ресурс). Лидеры общественного мнения подают пример. А пример, как его трактует В. Бехтерев, - это инструмент внушения. Лидеры мнения схватывают идеи, новости, комментарии от СМИ, трансформируют их, и заражают ими людей, находящихся рядом. Это уже «закрытая» жизнь массовых коммуникаций, связанная с управ- 
лением общественным мнением.

Действие системы «лидер мнения» - социальная группа» оригинально объяснила германский социолог Э. Ноэль-Нойман. Она считала, что общественное мнение - это ценностно окрашенное мнение и способ поведения, которые следует демонстрировать прилюдно, если не хочешь оказаться в изоляции. Как показывают исследования общественного мнения, давление оказывает не столько арифметическое большинство, сколько агрессивная уверенность одной стороны и страх перед изоляцией в сочетании с боязливым наблюдением за окружающей средой другой стороны (Ноэль-Нойман, 1996: 341).

Получается, что индивид выстраивает свое поведение под влиянием, во-первых, окружающей среды и ее сигналов об одобрении/неодобрении, во-вторых, под влиянием СМИ, в которых проявляются взаимно подтверждающие сигналы (Полуэхтова, 2012). Окружающая среда воздействует на человека своим общественным мнением, которое, в свою очередь, в значительной мере формируется СМИ и лидерами общественного мнения, выступающими проводниками позиций СМИ и заражающими людей своим примером в оценке этих позиций.

Взаимодействие окружающей среды, массовых коммуникаций и лидеров общественного мнения Э. Ноэль-Нойман представляет в образе «спирали молчания». Эта «спираль» закручивается тогда, когда люди, не желая оказаться в изоляции, постоянно наблюдают за своим окружением, отмечая, какое мнение усиливается под влиянием СМИ и «лидеров мнения». Кто видит, что его мнение находит все большую поддержку, тот высказывается прилюдно, становясь неким «вторичным» лидером общественного мнения. А кто видит, что его позиция не находит поддержки у других, - погружается в молчание. По отношению к нему процесс внушения ослабевает под давлением убеждения. Промолчавшие кажутся слабее на фоне тех, кто открыто, на виду у публики декларирует свою точку зрения и тем самым производит впечатление более сильного человека. В результате действительное большинство маскируется. Одни - они же «лидеры мнения» - побуждают других говорить или молчать до тех пор, пока одна из позиций не исчезнет (там же: 343).

Если Э. Ноэль-Нойман пришла к этим выводам в 50-е годы XX века, полагаясь на результаты своих исследований, то большой русский писатель А. Чехов близко подошел к таким же выводам в конце XIX века, основываясь на художественном исследовании российской действительности. В своем рассказе «Крыжовник» (1898 г.) устами одного из героев он говорит: «Вы взгляните на эту жизнь: наглость и праздность сильных, невежество и скотоподобие слабых, кругом бедность невозможная, теснота, вырождение, пьянство, лицемерие, вранье... Между тем во всех домах и 
на улицах тишина, спокойствие; из пятидесяти тысяч живущих в городе ни одного, который бы вскрикнул, громко возмутился. Мы видим тех, которые ходят на рынок за провизией, днем едят, ночью спят, которые говорят свою чепуху, женятся, старятся, благодушно тащат на кладбище своих покойников, но мы не видим и не слышим тех, которые страдают, и то, что страшно в жизни, происходит где-то за кулисами. Всё тихо, спокойно, и протестует одна только немая статистика: столько-то с ума сошло, столько-то ведер выпито, столько-то детей погибло от недоедания... И такой порядок, очевидно, нужен; очевидно, счастливый чувствует себя хорошо только потому, что несчастные несут свое бремя молча, и без этого молчания счастье было бы невозможно. Это общий гипноз» (Чехов, 1981: 538-539).

Но как выйти из этого гипноза? Чехов предлагает: «Надо, чтобы за дверью каждого довольного, счастливого человека стоял кто-нибудь с молоточком и постоянно напоминал бы стуком, что есть несчастные, что как бы он ни был счастлив, жизнь рано или поздно покажет ему когти, стрясется беда - болезнь, бедность, потери, и его никто не увидит и не услышит, как теперь он не видит и не слышит других. Но человека с молоточком нет, счастливый живет себе, и мелкие житейские заботы волнуют его слегка, как ветер осину, - и все обстоит благополучно» (там же: 539).

Конечно, молоточек, напоминающий о несчастных, - это коммуникации, несущие определенные образы. И тогда вопрос в том, а доходят ли те образы, что выступают в качестве молоточков? Особенность массовых коммуникаций - в их взаимодействии с общественным мнением, которое активно вторгается в сферу внушения. Это взаимодействие и создает эффект массового внушения - самого сильного психологического оружия. Слова и образы, транслируемые с помощью различных средств массовых коммуникаций, усиленные резонансом общественного мнения, интенсивным развитием социальных сетей, авторы которых активно оппонируют общественному вещанию, и создают эффект массового внушения. «Пройдя» через внутренний мир личности, «преодолев» общественное мнение, информация (по сути ее концентрированный «остаток») закрепляется в сознании, побуждая человека к действию (Макаревич, 2015).

По мнению Ф. Уэбстера, особенность либерального капитализма - это управление с помощью информации, то есть распространение сознательно используемых средств убеждения людей (Уэбстер, 2004: 257). Но чем отличается управление с помощью информации от манипулирования человеком, социальной группой? Манипулирование - это социально-психологическое воздействие на людей с целью изменения их впечатлений, их поведения при помощи определенных методов, приемов, технологий во имя скрытых целей манипулятора. Такие методы, 
приемы, технологии, обслуживающие интересы манипулятора, считаются насилием над личностью. Манипулирование основывается на доводах, рассчитанных на неосведомленность. А управление с помощью информации - процесс открытый, публичный, в ходе которого показываются все точки зрения, позиции, мнения, вся полемика вокруг них. И цель этого процесса - стимулирование осмысления ситуации.

Но управление с помощью информации неспособно обеспечить общественное доверие, общественную стабильность, когда элита общества, люди обладающие силой и влиянием, пренебрегают солидарностью с другими людьми, сочувствием к ним, пониманием справедливого и несправедливого, лишены морали и бескорыстия. Это относится и к лидерам общественного мнения.

\section{СПИСОК ЛИТЕРАТУРЫ}

Бехтерев, В. М. (2001) Внушение и его роль в общественной жизни. СПб. : Издательский дом «Питер».

Громов, И., Мацкевич, А., Семенов, В. (1996) Западная социология. СПб. : Издательство «Ольга».

Карпухин, О. И. (2012) Культура массовых коммуникаций // Знание. Понимание. Умение. № 2. С. 308-309.

Крауч, К. (2012) Странная не-смерть неолиберализма / пер. с англ. М. : Издательский дом «Дело» РАНХиГС.

Макаревич, Э. Ф. (2015) Об эффективности коммуникационного воздействия // Знание. Понимание. Умение. № 1. С. 106-127.

Макаревич, Э. Ф., Карпухин, О. И. (2008а) Культура массовых коммуникаций: сущность, тенденции, индикаторы (начало) // Знание. Понимание. Умение. № 3. С. 30-40.

Макаревич, Э. Ф., Карпухин, О. И. (2008b) Культура массовых коммуникаций: сущность, тенденции, индикаторы (окончание) // Знание. Понимание. Умение. № 4. С. 23-28.

Маркс, К., Энгельс, Ф. (1961) Сочинения : в 50 т. 2-е изд. М. : Госполитиздат. Т. 21.

Ноэль-Нойман, Э. (1996) Общественное мнение. Открытие спирали молчания. М. : Прогресс-Академия.

Парсонс, Т. (2000) О структуре социального действия. М. : Академический проект.

Полуэхтова, И. А. (2012) Социология массовых коммуникаций // Знание. Понимание. Умение. № 3. С. 243-249.

Социальные сети в России сегодня: цифры, тренды, прогнозы (2013) [Электронный ресурс] // Brand Analytics. Аналитика информационного поля бренда. 24 января. URL: http://br-analytics.ru/blog/?p=276 (дата обра- 
щения: 15.04.2015).

Уэбстер, Ф. (2004) Теории информационного общества. М. : АспектПресс.

Хабермас, Ю. (1996) Демократия. Разум. Коммуникации. Московские лекции и интервью. М. : AO «KAM1» ; издательский центр «ACADEMIA».

Чехов, А. П. (1981) Рассказы и повести. М. : Правда.

Макаревич Эдуард Федорович - доктор социологических наук, профессор кафедры философии, культурологии и политологии Московского гуманитарного университета. Адрес: 111395, Россия, г. Москва, ул. Юности, д. 5. Тел.: +7 (499) 374-55-11. Эл. адрес: edward.makarevich@mail.ru

Makarevich Eduard Fyodorovich, Doctor of Sociology, Professor, Department of Philosophy, Culturology and Politology, Moscow University for the Humanities. Postal address: 5 Yunosti St., 111395 Moscow, Russian Federation. Tel.: +7 (499) 374-55-11. E-mail: edward.makarevich@mail.ru 